\title{
Calculating and Modeling of an Indoor Water Consumption Factor in Mosul City, Iraq
}

\author{
Dr. Kossay K. Al-Ahmady \\ Environmental Engineering Depart ment, College of Engineering, University of Mosul, Iraq. \\ Rec. 20 Jun, 2011 Accpt. 18 July, 2011
}

\begin{abstract}
The growth of urban areas and constant need for potable water services, have highlighted the importance of accurate water consumption estimates for effective municipal water services infrastructure planning and design. A clear understanding of the drivers of residential water demand is essential in managing water resources appropriate as potable water. In this paper, a total of (1682) daily household water demand computations were carried out in order to calculate the actual indoor water consumption factor in the city of Mosul. The impacts of specific days of the week family size, water supply continuity and, seasonal variations (winter and summer) on water consumption were also considered. Results revealed that the daily average water consumption factors were $(126 \pm 65 \mathrm{Lcpd})$ in a winter season, $(235 \pm 64 \mathrm{Lcpd})$ in a summer season and the overall water consumption factor for the area was $(180 \pm 84 \mathrm{Lcpd})$. Water consumption was also found to be significantly correlated with explanatory variables. Seasonal variation plays the biggest role in controlling the water consumption factor followed by water supply continuity, then family size (negative effect) and in the last order specific days (weekends). General models to explain the effect of all of these parameters on the per capita water consumption were also derived in this paper.
\end{abstract}

Keywords: domestic water consumption, family size, modeling, water supply continuity, seasonal variation

\section{Introduction}

Water is a limited resource in Iraq. The river basins in Iraq cover only a small area and the tributaries that drain them are mostly seasonal in flow. Climate change coupled with increasing population, constructing large dams upstream, particularly outside Iraq, inefficient water use and the growing of urban areas have put stress on the existing water resources.

Domestic fresh water is a fundamental requirement for human welfare and economical activities (Keshavarzi, 2006). Domestic water consumption which is a significant component of the total water use is usually characterized by its use at homes and residences (Thomas, 1998). The water demand is affected by a variety of factors, such as family size, water supply pressure, days of week, how frequently water access is easy to get, climate conditions and people's consumption patterns. People's needs are not always the same. Therefore, identifying the factors that affecting domestic water consumption is very important in managing water resources appropriate as potable water (Keshavarzi, 2006).

Determining the actual daily water consumption per each person is one of the essential considerations in calculating the whole water needed for any community. In addition, this parameter is fundamental in the design of water supply and wastewater treatment facilities. Inaccurate estimates result in a deficiency in basic design information that could lead to inadequate service due to over-, or under-design of water supply infrastructure.

\footnotetext{
* Corresponding author:

Dr. Kossay K. Al-Ahmady

$\bowtie$ k.alahmady@yahoo.com
} 
A key input therefore in municipal water services planning and design is the estimation of present demand, and the prediction of future water demand.

The literature on residential water demand has expanded significantly in recent years in terms of scope and sophistication. One of the most continuous domestic water use databases was generated by the US Geological Survey, Solley et al., (1998). Analyses of the database revealed a continual increase in water use from 1950-1995 largely due to population increases.

(Anderson et al., 1980). investigated the effects of high rainfall and low temperatures on water use and found that high rainfall and reduced temperatures significantly restricted water use. (Maidment et al, 1986). assumed that water use can be separated into the base of winter and summer use and that the relationship between climate and water demand. (Woodard et al., 1988; Billings et al., 1989; Miaou, 1990; Stevens et al., 1992; Agthe et al., 1997; Martinez-Espiñeira, 2002 and Gutzler et al., 2005). studied the effects of climate and weather conditions on municipal water demands and concluded that, winter and summer temperatures significantly affect domestic water use.

(Howe et al., 1967; Foster et al., 1979; Garlipp, 1979; Nieswiadomy, 1992; Renwick et al., 1998; Arbués et al., 2000; Nauges et al., 2000; Piper, 2003; Jacobs et al., 2004 and Jacobs, 2007). investigated the effect of family size on domestic water consumption and pointed out that household size could be the most significant determinant of indoor water demand. (Edwards et al., 1995 and Stephenson et al., 1996). found that the parameters influencing water demand included water supply level of service, income, population density in the house, and housing type. (Cavanagh et al., 2002). commented on the significance of evaporative coolers use on household consumption. (Zyl et al., 2003). investigated the elasticity of water price, water pressure, and household income for residential water consumption. Water unit price was found to exert a significant impact on domestic water consumption patterns.
In Iraq, there were no serious studies dealing with the domestic water consumption issue. As a result, the domestic water consumption factors for the different areas of Iraq are still undetermined in addition, the affect of the associated social and environmental factors are still unclear. The principal aim of this study is to make estimates of residential water consumption factor for Mosul city as well as the effect of family size; specifying particular days of the week likely to increase supply consumption; the effect of summer and winter seasons; the effect of water supply continuity on the indoor water demand factor are also studied. Besides, the models that cover the effect of these parameters on the per capita indoor water consumption in city of Mosul is also established.

\section{Material and Methods}

Mosul is a city in northern Iraq. It is located about $(400 \mathrm{~km})$ northwest of Baghdad. Approximately (2.0) million people live in Mosul province and about (1.2) million people live in rural area of the governorate. The metropolitan area of the city stands on both banks of Tigris River. Mosul's climate varies, a hot semi-arid climate with extremely hot, almost rainless summers and cool, rainy winters. From April through November is the dry season when peak temperatures climb above (50) degrees Celsius. December through March is the rainy season with torrential downpours, flash flooding, and even snow (although rare and quick to dissipate). Most households in Mosul city have water supply connection.

In this paper, a total of (1682) daily household water consumption computations were carried out in order to calculate the indoor water consumption factor in city of Mosul. The selected households were of different sizes, types, social conditions and from various areas of the city. The chosen families were classified into (10) categories according to their sizes. In each family the actual indoor water consumption was measured. Table (1), provides statistical data for the family sizes, percentages, and the sample population for each family size. 
In order to determine the effect of day sequence in the week on the per capita water consumption, the measures were repeated throughout the day of week. Table (2), provides the number and percentage of measures carried out throughout each day of week. The average per capita water consumption for each individual day of week was calculated. The average per capita water use for each household size at each day was made from the calculated daily use. The individual household size and property type data were also subdivided into weekends and weekdays.

As water supply system in most of Iraqi cities and in city of Mosul is indirect, people generally use roof tanks to store water prior to using it domestically. Municipal water goes to these tanks either directly or by using separate booster pumps. This depends on the water supply pressure and continuity in that area.

Since there was a wide variation in water supply continuity within the different districts of city of Mosul, this parameter was considered in the calculation. Accordingly, water supply conditions were divided into three levels; good, medium, and bad. Good level means, water is available in that area continuously. Medium level means water is available in that area at irregular intervals (5) to (7) times per week. A bad condition means water is available in that area at irregular intervals, (2) to (3) times per week. Users with the bad water supply continuity usually use separate booster pumps to deliver water to the top tanks. Houses with the medium water supply condition mostly used the assistant pumps to deliver water to the roof tanks at the summer season.

To determine the effect of climate conditions on the indoor water consumption the calculations were repeated in both summer and winter seasons. The parameters considered in these measurements were; household size; days of week; water supply continuity and, the effects of summer and winter season.

Since water meters were not available in most of city of Mosul houses, the collection of water consumption data was a problem in this research. The computing process was carried out as follows: at a specific time of day (time $\mathrm{t}_{1}$ ), the tanks input valve was closed and the height of water in the tanks was measured and recorded $\left(h_{1}\right)$. The output valve was left open in order to allow water into the house. After (24) hours (time $t_{2}$ ) the height of water in the tank was re-measured and recorded $\left(\mathrm{h}_{2}\right)$, see figure (1). The difference between these two measurements $(\Delta \mathrm{h})$ multiplied by the surface area of the tank gives indicates the volume of water consumed within this period by this family. As noted, this process necessities visits to each house in order to collect data. The indoor water consumption is calculated as follows:

$$
\begin{aligned}
& V=\left(h_{1}-h_{2}\right)-A \\
& Y=\frac{V \times 1000}{\left[\left(t_{1}-t_{2}\right)-n\right]}
\end{aligned}
$$

Where:

$Y=$ Indoor water consumption dependent variable, Lcpd

$V$ : volume of water consumed during the time, $\left(\mathrm{m}^{3}\right)$

$h_{1}$ : initial height of water at time $\mathrm{t}_{1},(\mathrm{~m})$

$h_{2}$ : final height of water at time $\mathrm{t}_{2},(\mathrm{~m})$.

$A$ : Surface area of the tank, $\left(\mathrm{m}^{2}\right)$

$t_{1}$ : the commencing time in which the input valve was closed and the initial height of water was measured,

$t_{2}$ : the closing time in which the final height of water was measured, usually after 24 hours.

$n:$ Number of persons in the house.

All data were treated and analyzed in order to evaluate the effect of each parameter on the indoor water consumption variable. Individual mathematical models to describe the effect of each parameter were also derived during this study.

\section{Results and Discussion Effect of day sequence of the week}

Table (3) provides descriptive statistics for the sample population including water consumption ranges, means, and the standard deviations for each day of the week and both at winter and summer seasons. In figure (2), the effect of day of the week on per capita water consumption is represented. In this 
figure, a starting index from one to seven symbolized each day of week.

As seen from the figure, weekends, Fridays and Saturdays, (the off days in Iraq) had an impact on the per capita water consumption factor. Comparing per capita water consumption values in Fridays with the other weekday's values showed that there was an increasing in consumption rate of about $(30 \%, 33 \%, 37 \%, 30 \%$, and $17 \%)$ for Sunday, Monday, Tuesday, Wednesday, and Thursday respectively. Repeating same comparison for Saturday showed that the increasing ratios were $(20 \%, 23 \%, 27 \%, 20 \%$, and $8 \%)$ for the same days of week respectively. In summer seasons, these ratios were $(13 \%, 15 \%, 18 \%$, $12 \%$, and $12 \%)$ for Friday and $(8 \%, 10 \%, 13 \%$, $7 \%$, and $6 \%$ ) for Saturday respectively.

However, this result might be acceptable as more people stayed indoors during the weekends and hence were likely to consume more water. The other effective factor might be the school holidays. The specific process of how school holidays influence the indoor water demand was unknown. However, it was related undoubtedly to both children and adults staying at home. This finding confirms the results of (Bellfield, 2001 and Hranova, 2002).

\section{Effect of family size}

Figure (3) summarizes the influence of family size on per capita indoor water consumption values. Table (4) provides statistics for the sample population including consumption ranges, means, and the standard deviations at each family size and both at winter and summer seasons. As shown in the figure, family size had a negative effect on the per capita water consumption. That is, in households with larger families, average water consumption per person is reduced. The relation was not linear and seemed to be more sensitive in smaller family sizes than in larger ones. Comparing per capita water consumption values of family sizes of (7) $\mathrm{w}$ ith (4) persons showed that there were a decrease in demand at about $(27 \%)$ whereas this value decreased to about $(6 \%)$ for family sizes of (12) and (9) persons respectively. Similar behavior was also noted in a summer season.
To better understand the result of indoor water consumption can be segregated into person specific and family - specific water use. Family - specific water use that water which are relatively independent directly on the family size (e.g., uses for cooking, cleaning, washing clothes and dishes, etc.), so that while total water use per household rises, per capita water use falls as family size increases. This finding confirms the results of (Arbués, 2000; Klein, 2007; and Worthington, 2007). emphasizing that domestic water consumption is influenced by the increase in the number of single-family homes. The relation between water consumption and household size emphasized that an increase in water consumption can be better explained by the growth of the number of households than by population growth.

In order to quantify the indoor water consumption factor with household size, a least squares regression line was obtained. As shown in the figure, the logarithmic form of equations had proven to be efficient in representing this behavior. The coefficients of determination $\left(\mathrm{R}^{2}\right)$ for these equations were relative ly high and equal to $(0.945)$ and $(0.985)$ for both winter and summer seasons respectively which generally indicates a good fit.

\section{Effects of summer and winter seasons}

The effect of weather condition i.e. the summer and winter seasons, were given in tables (3) and (4) and figures (2) and (3). As noted in the tables and the figures, the hot and cold weather influenced significantly indoor water consumption factor. Comparing water consumption factors in both summer and winter seasons showed that there were an increase in consumptions at about $(87 \%, 93 \%$, $74 \%, 79 \%, 94 \%, 96 \%, 109 \%, 115 \%, 105 \%$ and $106 \%)$ at family sizes of $(3,4,5,6,7,8,9$, 10,12 , and 14) persons respectively. The possible influence of climate variability on water demand might be very different in various climatic regimes. However, diversity of water consumption activities during the hot climate and repetition of some activities such as: washings, cleaning, cloths washings which might increase in hot climate rather than in cold one may be the reasons responsible for 
this growth. In addition, presence of evaporative coolers in a summer season had a significant effect in increasing water consumption regardless of the number of family in the house which also explains such an increase in consumption. This finding confirms the results of (Cavanagh, 2002; Gutzler, 2005; Jacobs, 2004; Kle in, 2007; Miaou, 1990). Another factor is being the school holiday in the summer season (Bellfield, 2001).

\section{Effect of water supply continuity}

The quality of water services is judged by its continuity and degree of water pressure. The results of the study showed that, only (9\%, $\mathrm{n}=154$ ) of the dwellings in city of Mosul had a good water supply continuity. About $(27 \%, \mathrm{n}$ $=458$ ) of the houses had medium water supply remaining; the $(64 \%, \mathrm{n}=1070)$ of houses had bad water supply continuity. In figure (4) the values of indoor water consumption factor are plotted against the water supply continuity at both of summer and winter seasons. The data analysis showed that, water supply continuity strongly influenced the indoor water consumption factor. The reasons of that might be attributed to the people behavior. People usually tend to use a lot of water as long as it is available. At medium and bad water supply continuity, the discontinuity of water forced people to use lesser amount.

As shown in figure (4), the linear model had proven to be efficient in representing the effect of water supply continuity on water consumption factor. The coefficient of determination $\left(\mathrm{R}^{2}\right)$ was high and amounted to (0.99) for both of the winter and summer seasons.

\section{The indoor wate $r$ cons umption factor}

Per capita water consumption factor was calculated for each individual home using daily water use during the summer and winter survey. Averages of per capita use were made from the daily per capita use calculated for each household. Table (3) shows the ranges and average values of indoor water consumption factor for different week days and at summer and winter seasons. Table (4) shows these values for different family sizes. Results of the study revealed that the daily average water consumption factor for the winter seasons is ( $126 \pm 65 \mathrm{Lcpd}, \mathrm{n}=836)$, for the summer season is $(235 \pm 64 \mathrm{Lcpd}, \mathrm{n}=$ $846)$, and the overall average water consumption factor for the area is $(180 \pm 84$ Lcpd).

As shown in tables (3 and 4), there were variations in per capita water consumption for each group of family size and week days. These were due to variations in water supply continuity and other social and environmental factors. Similar variation in water consumption factors were also noted by other researchers (Arbués, 2003; Jacobs, 2007; Mayer, 1999; Zyl, 2008). Comparing the total mean indoor water consumption factors with that recorded in neighboring country (Burak, 2009). showed that, this value was relatively low. The reason of that was due to shortage of water supply continuity in the city of Mosul.

In figure (5), the probability distribution of the per capita indoor water consumption values were represented at both summer and winter seasons. As shown in the figure, about $(6 \%)$ of readings had values equaled to or less than (50 Lcpd); $(47 \%)$ of readings had values equal to or less than (100 Lcpd) while $(61 \%)$ of readings had values equal to or less than the mean water consumption at winter season. Only $(14 \%)$ of readings had values greater than $(200 \mathrm{Lcpd})$ with $(7 \%)$ greater than $(250$ Lcpd). In summer season, about (17\%) and (36\%) of readings had values equal to or less than (175 and $200 \mathrm{Lcpd}$ ) respectively. (60\%) of readings had values equal to or less than the mean value of the per capita water consumption. While (17\%) of the records were found to have values greater than $(300 \mathrm{Lcpd})$ with $(4 \%)$ greater than $(400$ Lcpd $)$ respectively.

For better understanding the relation between water consumption patterns and days of week the property data were subdivided into two groups weekends and weekdays. One-way ANOVA statistics was used to compare household consumption factor with respect to these two groups. The results, shown in Table (5), reveal that there was no significant difference $(\mathrm{F}=0.794, \mathrm{p}>0.05)$ between the days of week (Sunday, Monday, Tuesday, Wednesday, and Thursday) and they 
can be considered as one group with respect to calculate household consumption factor. Table (6) also reveals that there was no significant difference $(\mathrm{F}=2.25, \mathrm{p}>0.05)$ between the weekends (Friday and Saturday) and they can be considered as one group.

To understand the relationship between water consumption factor and the variables affecting the consumption, a correlation matrix was constructed using (5) variables (Table 7). As it can be seen from the correlation matrix, there was a significant correlation between water consumption and the independent variables. The most important variable affecting water consumption was the seasonal variation which had a significant correlation with water consumption $(\mathrm{r}=0.65$, $\mathrm{p}<0.01)$. While it is believed that the amount of indoor water use remains fairly constant throughout the year, it actually varies greatly depending on seasonal variation. Another variable which showed a statistically significant correlation with domestic water consumption was water continuity. Table (7) shows that there is a positive significant relationship between water continuity and the amount of indoor water consumption factor $(\mathrm{r}$ $=0.648, p<0.01$ ). That means the variability of water consumption depends considerably on water availability. Table (7) also reveals that the family size had the expected negative correlation with water consumption $(\mathrm{r}=-0.286$, $\mathrm{p}<0.01$ ), In other words, households with higher per capita water consumption were those with smaller families. Weekends had also significant correlation with water consumption factor $(\mathrm{r}=0.147, \mathrm{p}<0.01)$.

\section{Mode ling of water cons umption}

To analyze the impact of various parameters on the per capita indoor water consumption factor in Mosul city, a stepwise multiple regression analysis was performed. The regression analyses were, however, very useful in identifying the most important parameters influencing water consumption.

Assuming that the per capita indoor water consumption depends on family sizes, water supply continuity and the climate conditions, the following expression can be written:

$$
Y=f(C C, W C, F S)
$$

Where:

$Y$ : per capita indoor water consumption, Lcpd

$C C$ : Climate condition,

$W C$ : Water supply continuity,

$F S$ : Family size, (3-14 persons).

Two dummy variables are needed to symbolize the water supply continuity and the climate condition. The dummy variables were incorporated into the model by creating new variables NCC and NWC. As noted in figures (3), the logarithmic form of equations had proven to be efficient in representing the effect of family size on water consumption factor. For weekdays (Sunday, Monday, Tuesday, Wednesday, and Thursday) equation (3) can be rewritten as:

$Y=\beta_{0}+\beta_{1}(N C C)+\beta_{2}(N W C)+\beta_{3}(\ln F S) \ldots$.

Where:

$B_{0}, \beta_{1} \ldots \beta_{3}$ : Constants

$N C C$ : Number of climate condition, (Winter $=1$, Summer $=2$ ),

$N W C$ : Number of water supply continuity, $(\mathrm{Bad}=1$, Medium $=2$, Good = 3),

FS: Family size, (3-14 persons).

The water consumption model for weekends (Friday and Saturday) is represented by following relationship:

$Y=\phi_{0}+\phi_{1}(N C C)+\phi_{2}(N W C)+\phi_{3}(\ln F S)$

Where $\left(\square_{0}, \square_{1}, \square_{2}, \square_{3}\right)$ are constants. All the derivatives in equation (4) and (5) were calculated numerically using (SPSS) program. Equations (6) and (7) provide the general solution of the equation (4) and (5) respectively;

$Y=-1.272+110.105(N C C)+78.849(N W C)-54.943(\ln F S) \ldots(6)$

$Y=51.92+109.728(N C C)+83.194(N W C)-73.218(\ln F S) \ldots .(7)$

Equation (6) can be used to explain household water consumption variation at weekdays (Sunday, Monday, Tuesday, Wednesday, and Thursday), whereas, equation (7) can be used to calculate the indoor consumption factor at weekends.

In tables (8) and (9), the outputs of the statistical solution of the models were presented. As noted in the tables, the fitting of the models is good. Both of the coefficient of correlation $\left(\mathrm{R}^{2}\right)$ and adjusted $\left(\mathrm{R}^{2}\right)$ values are high and equal to $(91.7 \%$ and $91.7 \%)$ and (93.1\% and 93\%) for models (6) and (7) 
respectively. The tables reveal significant relationships between the household water consumption factor and the selected independent variables $(\mathrm{F}=3965.47, \mathrm{P}<$ $0.001)$ and $(\mathrm{F}=2683.35, \mathrm{P}<0.001)$ for both the models respectively.

In table (10) and (11), the weights and significant of each variable in the mode ls were represented. As reflected by the Beta standardized coefficients the season (Summer or Winter) plays the biggest role in controlling the water consumption factor followed by water supply continuity, then the family size. The results, shown in the tables reveal that the seasonal variation has about (2.94) and (2.34) times the effect of family size in both models respectively. On the other hand both seasonal variations and water continuity have an evenly effect. The tables also show significant relationship between household water consumption factor and each single independent variable in the models $(\mathrm{P}<0.001)$. The $\mathrm{t}$ - test illustrates that each of the $X$ variable parameter is statistically significantly different from zero.

\begin{tabular}{|c|c|c|c|c|c|c|}
\hline $\begin{array}{c}\text { Family size, } \\
\text { (person) }\end{array}$ & $\begin{array}{c}\text { Number of } \\
\text { families }\end{array}$ & $\begin{array}{c}\text { \% of } \\
\text { total }\end{array}$ & $\begin{array}{c}\text { Number of } \\
\text { readings, } \\
\text { Winter }\end{array}$ & $\begin{array}{c}\text { Number of } \\
\text { readings, } \\
\text { Summer }\end{array}$ & Total & $\begin{array}{c}\text { \% of } \\
\text { total }\end{array}$ \\
\hline 3 & 3 & 1.83 & 20 & 22 & 42 & 2.49 \\
\hline 4 & 6 & 3.66 & 30 & 32 & 62 & 3.69 \\
\hline 5 & 19 & 11.58 & 149 & 143 & 292 & 17.36 \\
\hline 6 & 40 & 24.39 & 207 & 203 & 410 & 24.38 \\
\hline 7 & 24 & 14.63 & 92 & 96 & 188 & 11.18 \\
\hline 8 & 20 & 12.19 & 89 & 91 & 180 & 10.7 \\
\hline 9 & 19 & 11.58 & 96 & 98 & 194 & 11.53 \\
\hline 10 & 17 & 10.37 & 58 & 64 & 122 & 7.25 \\
\hline 12 & 12 & 7.32 & 57 & 59 & 116 & 6.90 \\
\hline 14 & 4 & 2.44 & 38 & 38 & 76 & 4.52 \\
\hline Total & 164 & 100 & 836 & 846 & 1682 & 100 \\
\hline
\end{tabular}

Table (1): Fa mily sizes, nu mber of families and number of each corresponding computations carried out in the study

\begin{tabular}{|c|c|c|c|c|}
\hline Day of week & $\begin{array}{c}\text { Number of readings, (n), } \\
\text { Winter }\end{array}$ & $\begin{array}{c}\text { Number of readings, (n), } \\
\text { Summer }\end{array}$ & Total & $\begin{array}{c}\text { \% of } \\
\text { total }\end{array}$ \\
\hline Sunday & 132 & 129 & 261 & 15.51 \\
\hline Monday & 107 & 106 & 213 & 12.67 \\
\hline Tuesday & 95 & 102 & 197 & 11.71 \\
\hline Wednesday & 102 & 103 & 205 & 12.19 \\
\hline Thursday & 100 & 102 & 202 & 12.01 \\
\hline Friday & 171 & 171 & 342 & 20.34 \\
\hline Saturday & 129 & 133 & 262 & 15.57 \\
\hline Total & 836 & 846 & 1682 & 100 \\
\hline
\end{tabular}

Table (2): Nu mber of indoor water consumption measurements carried out throughout each day of week 


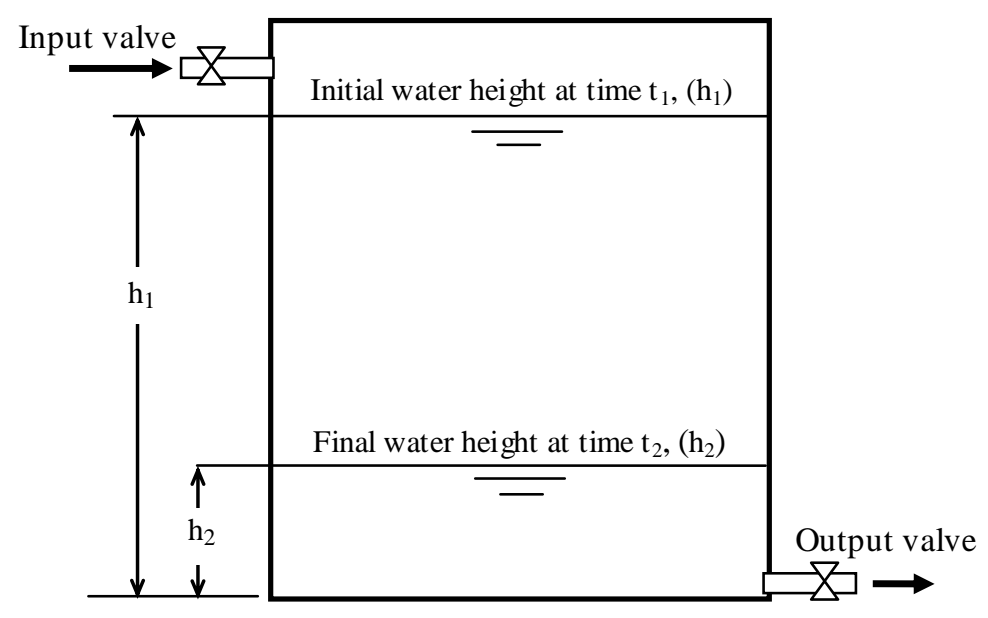

Fig. (1): Schematic of house reservoir

\begin{tabular}{|c|c|c|c|c|c|c|}
\hline \multirow{3}{*}{ Day of week } & \multicolumn{6}{|c|}{ Indoor water consumpti on factor, (Lcpd) } \\
\cline { 2 - 7 } & Range & Mean & SD & Range & Mean & SD \\
\cline { 2 - 7 } & $45-316$ & 118.79 & 60.11 & $140-388$ & 228.49 & 56.75 \\
\hline Sunday & $46-362$ & 111.31 & 63.50 & $143-405$ & 225.55 & 61.51 \\
\hline Monday & $47-308$ & 108.94 & 59.22 & $155-391$ & 217.64 & 59.70 \\
\hline Tuesday & $51-288$ & 113.57 & 58.04 & $148-399$ & 228.67 & 59.99 \\
\hline Wednesday & $53-297$ & 126.99 & 66.65 & $151-377$ & 229.44 & 60.21 \\
\hline Thursday & $62-322$ & 147.16 & 66.21 & $145-413$ & 256.52 & 68.68 \\
\hline Friday & $55-327$ & 136.57 & 65.28 & $153-433$ & 244.31 & 65.23 \\
\hline Saturday & &
\end{tabular}

Table (3): Ranges, means and standard deviations of household water consumption factor for different days of week both at winter and summer seasons.

\begin{tabular}{|c|c|c|c|c|c|c|}
\hline \multirow{2}{*}{$\begin{array}{c}\text { Family size, } \\
(\text { Person) }\end{array}$} & \multicolumn{5}{|c|}{ Indoor water consumption factor, (Lcpd) } \\
\cline { 2 - 7 } & Range & Mean & SD & Range & Mean & SD \\
\hline & $73-294$ & 154.81 & 36.62 & $173-341$ & 295.68 & 28.27 \\
\hline 3 & $66-214$ & 150.54 & 40.44 & $220-351$ & 292.06 & 37.19 \\
\hline 4 & $59-362$ & 149.11 & 77.36 & $176-390$ & 261.15 & 68.01 \\
\hline 5 & $62-322$ & 139.73 & 64.91 & $158-433$ & 251.68 & 63.32 \\
\hline 6 & $64-310$ & 119.55 & 48.54 & $155-413$ & 230.99 & 50.42 \\
\hline 7 & $59-301$ & 116.27 & 67.21 & $151-354$ & 226.56 & 65.10 \\
\hline 8 & $54-279$ & 100.49 & 43.48 & $154-365$ & 208.97 & 44.29 \\
\hline 9 & $46-301$ & 98.12 & 49.81 & $156-377$ & 201.8 & 49.40 \\
\hline 10 & $49-308$ & 95.6 & 50.1 & $158-371$ & 195.86 & 47.49 \\
\hline 12 & $47-223$ & 88.45 & 53.9 & $140-328$ & 180.68 & 51.72 \\
\hline 14 & &
\end{tabular}

Table (4): Ranges, means and standard deviations of household consumption factor for different family sizes both at winter and summer seasons. 


\begin{tabular}{|r|c|c|c|c|c|}
\hline \multicolumn{7}{|c|}{ ANOVA } \\
\hline & Sum of Squares & df & Mean S quare & F & Sig. \\
\hline Between Groups & 21269.840 & 4 & 5317.460 & .794 & .529 \\
\hline Within Groups & 7183931.516 & 1073 & 6695.183 & & \\
\hline Total & 7205201.356 & 1077 & & & \\
\hline Water consumption factor, Lcpd
\end{tabular}

Table (5): Co mparis on weekdays effect with respect to household consumption factor.

\begin{tabular}{|r|c|c|c|c|c|}
\hline \multicolumn{7}{|c|}{ ANOVA } \\
\hline & Sum of S quares & df & Mean S quare & F & Sig. \\
\hline Between Groups & 16594.630 & 1 & 16594.630 & 2.251 & .134 \\
\hline Within Groups & 4437391.091 & 602 & 7371.082 & & \\
\hline Total & 4453985.722 & 603 & & & \\
\hline Water consumption factor, Lcpd
\end{tabular}

Table (6): Co mparis on weekends effect with respect to household consumption factor.

\begin{tabular}{|l|c|c|c|c|c|}
\hline & $\begin{array}{c}\text { Water consumption } \\
\text { factor, Lcpd }\end{array}$ & Weekends & $\begin{array}{c}\text { Water } \\
\text { continuity }\end{array}$ & Family size & Season \\
\hline $\begin{array}{l}\text { Water consumption } \\
\text { factor, Lcpd }\end{array}$ & 1 & $.147(* *)$ & $.648(* *)$ & $-.286(* *)$ & $.650(* *)$ \\
\hline Weekends & $.147(* *)$ & 1 & .015 & -.020 & .001 \\
\hline Water continuity & $.648(* *)$ & .015 & 1 & $-.085(* *)$ & -.002 \\
\hline Family size & $-.286(* *)$ & -.020 & $-.085(* *)$ & 1 & .007 \\
\hline Season & $.650(* *)$ & .001 & -.002 & .007 & 1 \\
\hline
\end{tabular}

Table (7): Correlation matrix between indoor water consumption factor and the independent variables ** Correlation is significant at the 0.01 level (2-tailed). $\mathrm{N}=1682$

\begin{tabular}{|l|c|c|c|c|c|}
\hline \multicolumn{7}{|l|}{ ANOVA } \\
\hline & Sum of S quares & df & Mean S quare & F & Sig. \\
\hline Regression & 6608583.791 & 3 & 2202861.264 & 3965.477 & $.000(\mathrm{c})$ \\
\hline Residual & 596617.565 & 1074 & 555.510 & & \\
\hline Total & 7205201.356 & 1077 & & & \\
\hline Dependent Variable: water consumption factor, Lcpd \\
\hline R Square $=.917$ \\
\hline Adjusted R Square $=.917$
\end{tabular}

Table (8): Statistical outputs of the solution of the equation (6) 


\begin{tabular}{|l|c|c|c|c|c|}
\hline \multicolumn{7}{|l|}{ ANOVA } \\
\hline & Sum of Squares & df & Mean S quare & F & Sig. \\
\hline Regression & 4145040.961 & 3 & 1381680.320 & 2683.354 & $.000(\mathrm{c})$ \\
\hline Residual & 308944.761 & 600 & 514.908 & & \\
\hline Total & 4453985.722 & 603 & & & \\
\hline Dependent Variable: water consumption factor, Lcpd \\
\hline R Square = .931 \\
\hline Adjusted R Square $=.930$
\end{tabular}

Table (9): Statistical outputs of the solution of the equation (7)

\begin{tabular}{|l|c|c|c|c|c|}
\hline \multicolumn{7}{|c|}{ Coefficients } \\
\hline & Unstandar dized Coefficients & Standar dized Coefficients & \multirow{2}{*}{ t } & \multirow{2}{*}{ Sig. } \\
\cline { 2 - 5 } & $\mathrm{B}$ & Std. Error & Beta & -.252 & .801 \\
\hline (Constant) & -1.272 & 5.042 & & 76.683 & .000 \\
\hline Season & 110.105 & 1.436 & .673 & 70.967 & .000 \\
\hline Water continuity & 78.849 & 1.111 & .625 & -26.015 & .000 \\
\hline ln of family size & -54.943 & 2.112 & -.229 & & \\
\hline
\end{tabular}

Table (10): Weight and significant of each variable in the model (6)

\begin{tabular}{|c|c|c|c|c|c|}
\hline \multicolumn{6}{|c|}{ Coefficients } \\
\hline & \multicolumn{2}{|c|}{ Unstandar dized Coefficients } & \multirow{2}{*}{$\frac{\text { Standar dized Coefficients }}{\text { Beta }}$} & \multirow{2}{*}{$\mathbf{t}$} & \multirow{2}{*}{ Sig. } \\
\hline & $\mathrm{B}$ & Std. Error & & & \\
\hline (Constant) & 51.925 & 6.692 & & 7.759 & .000 \\
\hline Water continuity & 83.194 & 1.380 & .651 & 60.302 & .000 \\
\hline Season & 109.727 & 1.847 & .639 & 59.414 & .000 \\
\hline $\ln$ of family size & $\begin{array}{l}-73.218 \\
\end{array}$ & 2.829 & $\begin{array}{l}.279 \\
\end{array}$ & -25.885 & .000 \\
\hline
\end{tabular}

Table (11): Weight and significant of each variable in the model (7)

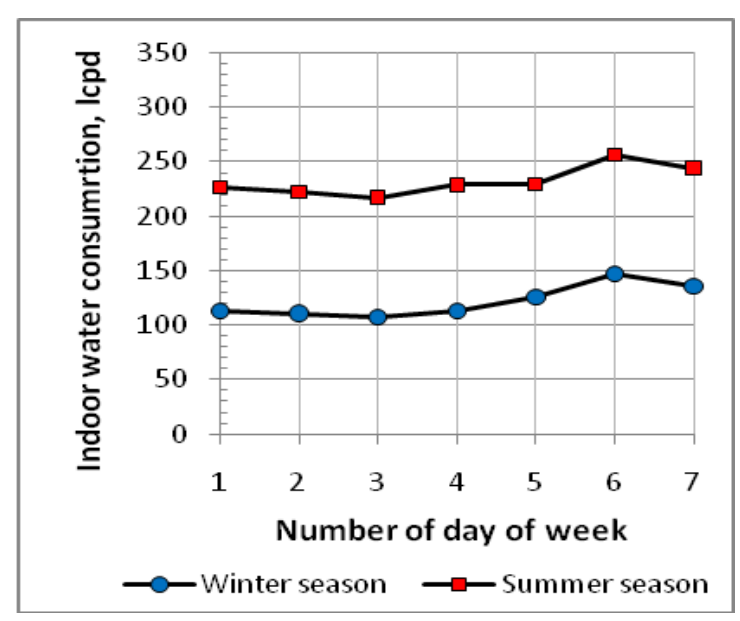

Fig (2): Relationship between the average indoor water consumption factor and days of week at summer and winter seasons $(1=$ Sunday, 2 = Monday, $3=$ Tuesday, $4=$ Wednesday, $5=$ Thursday, $6=$ Friday, $7=$ Saturday)

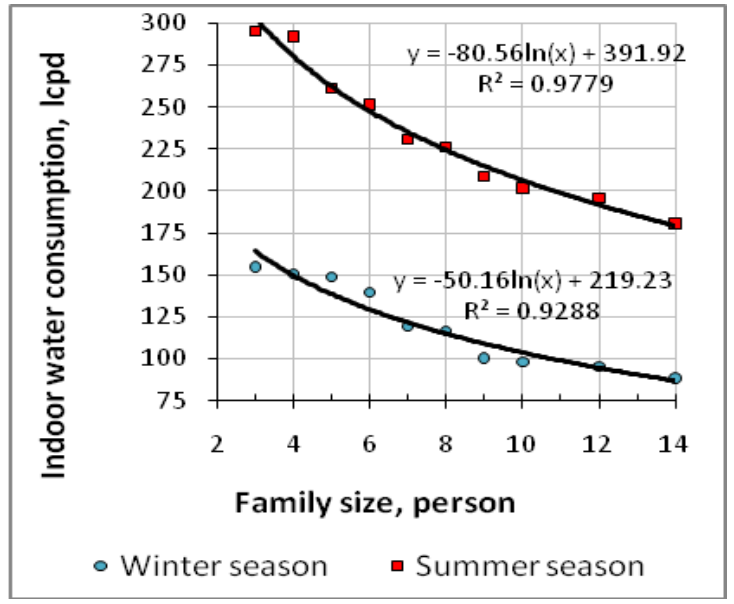

Fig (3): Relationship between the average indoor water consumption factor and family sizes at summer and winter seasons 


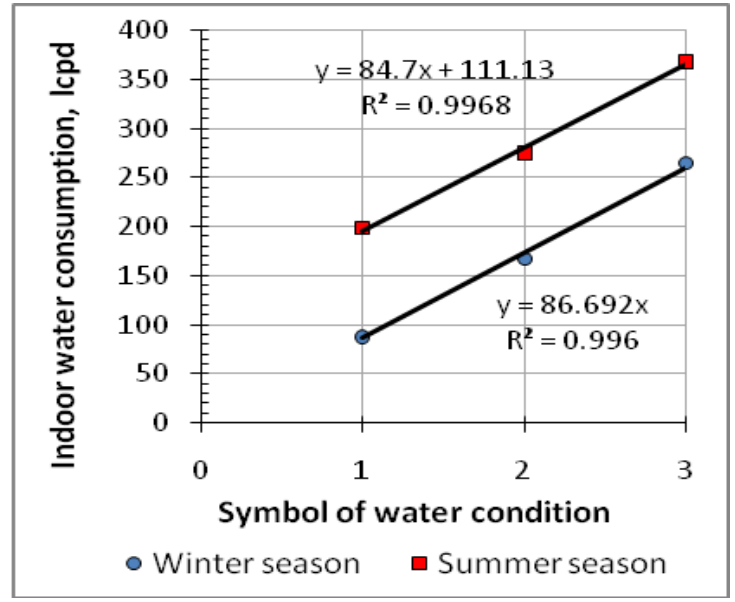

Fig (4): Relationship between the average indoor water consumption factor water supply at summer and winter seasons. $(\operatorname{Bad}=1$, Medium $=2, \operatorname{Good}=$ 3)

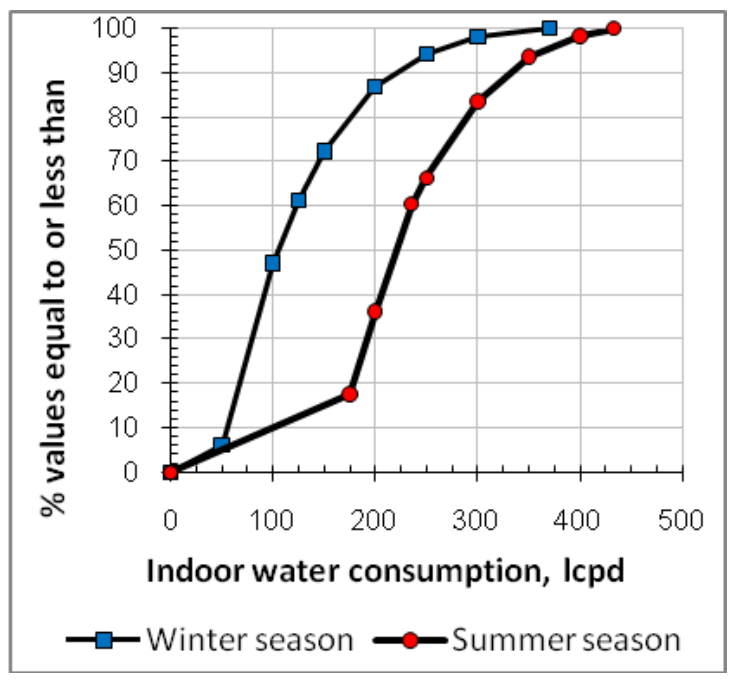

Fig (5): Probability distribution plot for the values of indoor water consumption factor at summer and winter seasons

\section{Conclusion}

1. Water conservation is important in ensuring a sustainable future for households especially in arid and semi arid regions like Iraq.

2. The growth of urban areas and constant need for potable water services, have highlighted the importance of accurate water consumption estimates for effective municipal water services infrastructure planning and design.

3. Daily average water consumption factors were $(126 \pm 65 \mathrm{Lcpd})$ in winter season, $(235 \pm 64$ Lcpd $)$ in summer season and the overall water consumption factor for the area was (181 \pm 84 Lcpd).

4. The above residential water consumption factors, together with the estimated population for each municipal section, can be used to estimate the daily water consumption for different district of Mosul city and at different conditions.

5. Water consumption was found to be significantly correlated with explanatory variables such as seasonal variation, water supply continuity and family size.

6. Seasonal variation plays the biggest role in controlling the water consumption factor followed by water supply continuity, then family size (negative effect) and in the last order weekends.

7. Per capita water consumption factor in Mosul city can be effectively represented using linear multiple regression models.

\section{References}

Abouzaid, H. (2003). Water scarcity, pollution and health, WHO/UNEP $1^{\text {st }}$ regional conference on water demand management, conservation and pollution control, Amman, Jordan 7-10 October.

Agthe, D.E. and Billings, R.B. (1997). Equity and Conservation Pricing Policy For a Government Run Water Utility, Journal of Water Supply Research and Technology Aqua, 46(5):252-260.

Anderson, R.L., Miller, T.A. and Washburn, M.C. (1980). Water Savings from lawn Watering Restrictions during a Drought Year, Fort Collins, Colorado, Water Resources Bulletin 16(4):642-646.

Arbués, F., Barberán, R. and Villanúa, I. (2000). Water Price Impact on Residential Water Demand in The City of Zaragoza. A Dynamic Panel Data Approach. Paper presented at the 40th European Congress of the European Regional Studies Association (ERSA) in Barcelona, Spain, 30-31 August.

Arbués, Fernando, Maria Angeles Garcia-Valinas, and Roberto Martinez-Espineira, (2003). 
Estimation of Residential Water Demand: A State-of-the-art Review, Journal of Socio-Economics, 32:81-102.

Bakir, H. (2003). Water demand management and pollution control key to securing and safeguarding the water supplies of the eastern Mediterranean region in the $21^{\text {st }}$ century, WHO/UNEP $1^{\text {st }}$ regional conference on water demand management, conservation and pollution control, Amman, Jordan 7-10 October.

Bellfield, S. L. (2001). Short Term Domestic Water Demand: Estimation, Forecasting and Management, $\mathrm{PhD}$ Thesis, University of Leeds.

Billings, R.B. and Day, W.M. (1989). Demand Management Factors in Residential Water Use: The Southern Arizona Experience, Journal AWWA, 81(3):58-64.

Burak, S. and Mat, H. (2009). Municipal Water Demand and Efficiency Analysis: Case Studies in Turkey, Water Policy, (IWA publishing, article in press)

Cavanagh, S. M., Hanemann, Michael, W. and Stavins, R.N. (2002). Muffled Price Signals: Household Water Demand under Increasing-Block Prices. June. FEEM Working Paper No. 40, 2002.

Cheruseril, J.J. (2007). Determining an Urban Water Consumption Model Based On Socio-Demographic Factors, M.Sc. Thesis, Rmit University, February.

Cochran, R. and Cotton, A.W. (1985). Municipal Water Demand Study, Oklahoma City and Tulsa, Oklahoma, Water Resources Research, 21(7):941-943.

David, C. and Inocencio, A. (1996). Understanding Household Demand and Supply of Water: the Metro Manila Case, Philippine Institute for Developing Studies, December.

Edwards, K. and Martin, L. (1995). A Methodology for Surveying Domestic Water Consumption, J. Chartered Inst. Water and Environ. Manage, 9(10) 477488.

Fars, Province Rural Water and Wastewater Department (FPRWWD), (2004). Annual Report.

Foster, H.S. and Beattie, B.R. (1979). Urban Residential Demand for Water in the United States, Land Economics, 55(1):4358.

Garlipp, K. (1979). Water Consumption Patterns in Urban Areas, M.Sc. Dissertation.
University of Pretoria, Pretoria, South Africa.

Gutzler, D.S. and Nims, J.S. (2005). Interannual Variability Of Water Demand and Summer Climate in Albuquerque, New Mexico. Journal of Applied Meteorology 44:1777-1787, December.

Howe, C.W. and Goemans, C. (2002). Effectiveness of Water Rate Increases Following Watering Restrictions, Journal of the American Water Works Association, 28-32, August.

Howe, C.W. and Linaweaver, F.P. (1967). The Impact of Price on Residential Water Demand and its Relationship to System Design and Price Structure, Water Resources Research, 3(1):13-32.

Hranova, R.K. (2002). Variations of Potable Water Supply in High-Density Urban Areas, Zimbabwe, 3rd Water Net- Warfsa Symposium "Water Demand Management for Sustainable Development", Dar es Salaam, 30-31 October.

Jacobs, H., Geusteyn, L., Loubser, B., and Vander, M. (2004). Estimating residential water demand in Southern Africa, J. S. Afr. Inst. Civ. Eng. 46 (4) 2-13.

Jacobs, H. (2007). The First Reported Correlation Between End-Use Estimates of Residential Water Demand and Measured Use in South Africa. Water SA, 33(4).

Jacobs, H. and Haarhoff, J. (2004). Application of a Residential End-Use Model For Estimating Cold And Hot Water Demand, Wastewater Flow And Salinity, Water SA, 30(3).

Jacobs, H. and Haarhoff, J. (2004). Structure and Data Requirements of an End Use Model For Residential Water Demand And Return Flow, Water SA, 30(3).

Keshavarzi, A.R., Sharifzadehb, M., Kamgar Haghighia, A.A., Amina, S., Keshtkara, Sh, and Bamdada, A. (2006). Rural domestic water consumption behavior: A case study in Ramjerd area, Fars province, I.R. Iran, Water Research, 40: 1173 1178

Klein, B., Kenney, D., Lowrely, J. and Goemans, C. (2007). Factors Influencing Residential Water Demand: A Review of the Literature, Working Paper 1.12.07.

Kulshreshtha, S.N. (1996). Residential Water Demand In Saskatchewan Communities: Role Played by Block Pricing System in Water Conservation, Canadian Water Resources Journal, 21(2):139-155. 
Maidment, D.R. and Miaou, S.P. (1986). Daily Water Use in Nine Cities, Water Resources Research, 22(6):845-885.

Martinez-Espineira, R. (2002). Residential Water Demand in the Northwest of Spain, Environmental and Resource Economics, 21:161-187.

Mayer, P. and DeOreo, W., Opitz, E., Kiefer, J., Davis, W., Dziegielewski, B., and Nelson, J.O. (1999). Residential End Use of Water, American Work Association Research Foundation AWWARF, Denver, CO.

Miaou, S.P. (1990). A Class of Time-Series Urban Water Demand Models Nonlinear Climatic Effects, Water Resources Research, 26(2):169-178.

Morgan, W.D. and Smolen, J.C. (1976). Climatic Indicators in the Estimation of Municipal Water Demand, Water Resources Bulletin 12(3):511-518.

Nauges, C. and Thomas, A. (2000). PrivatelyOperated Water Utilities, Municipal Price Negotiation, and Estimation of Residential Water Demand: The Case of France, Land Economics, 76 (1):68-85.

Nieswiadomy, M.L. (1992). Estimating Urban Residential Water Demand: Effects of Price Structure, Conservation, and Education, Water Resources Research 28(3): 609- 615.

Otaki, Y., Otaki, M., Pengchai, P., Ohta, Y. and Aramaki, T. (2008), Micro ccomponents survey of residential indoor water consumption in Chiang Mai, Drinking water engineering and science, 45-70.

Piper, S. (2003). Impact of Water Quality On Municipal Water Price And Residential Water Demand And Implications For Water Supply Benefits, Water Resources Research, 39(5): 1127-1138.

Renwick, M.E. and Archibald, S.O. (1998). Demand Side management Policies for
Residential Water Use: Who Bears the Conservation Burden?, Land Economics, 74(3): 343-359.

Solley, W., Pierce, R. and Perlman, H. (1998). Estimated Use of Water in the United States in 1995, US Department of the Interior, US Geological Society. Denver, CO: USGS.

Stephenson, D. and Turner, K. (1996). Water demand patterns in Gauteng. IMIESA 21 (1): 11-16.

Stevens, T.H., Miller, J. and Willis, C. (1992). Effect of price structure on residential water demand, Water Resources Bulletin, 28(4): 681-685.

Thomas, T. (1998). Definition of water security (personnel communication) Trivandram Planning Meeting, August 1998.

Woodard, G.C. and Horn, C. (1988). Effects of Weather and Climate on Municipal Water Demand in Arizona. Report prepared for Arizona Department of Water Resources and Tucson Water.

World, H., Organization, W.H.O. (2005). Minimum water quantity needed for domestic use in emergencies, Technical Note No. 9, July.

Worthington, A.C., and Hoffman, M.A. (2007). State of the Art Review of Residential Water Demand Modeling, Accounting and Finance Working Paper 07/06, School of Accounting and Finance, University of Wollongong.

Zyl, V.H. and Husselman, M. (2003). Potential Application of End-Use Demand Modeling in South Africa, J. S. Afr. Inst. Civ. Eng. 45 (2): 9-19.

Zyl, V.H. and Llemobada, A.A. and Zyl, V.J. (2008). An Improved Area Based Guidline For Domestic Water Demand Estimation In South Africa, Water S.A. 34 (3): 381-392. 
Journal of Environmental Studies [JES] 2011. 6:39-52 